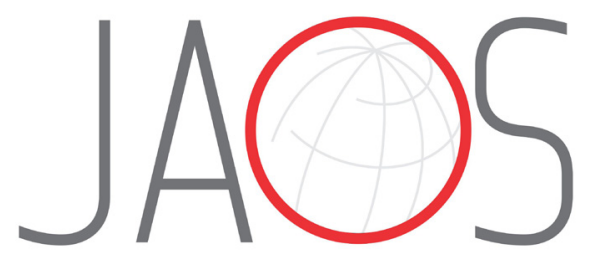
JOURNAL OF APPLIED ORAL SCIENCE

\title{
BMI-1 expression increases in oral leukoplakias and correlates with cell proliferation
}

\section{Abstract}

Isadora Peres KLEIN ${ }^{1}$ Luise MEURER ${ }^{2}$ Chris Krebs DANILEVICZ ${ }^{1}$ Cristiane Helena SQUARIZE ${ }^{3}$ Manoela Domingues MARTINS ${ }^{1}$ Vinicius Coelho CARRARD ${ }^{1}$
Submitted: September 26, 2019 Modification: December 6, 2019 Accepted: January 9, 2020
Oral leukoplakia (OL) is a white lesion of an indeterminate risk not related to any excluded (other) known diseases or disorders that carry no increased risk for cancer. Many biological markers have been used in an attempt to predict malignant transformation; however, no reliable markers have been established so far. Objective: To evaluate cell proliferation and immortalization in OL, comparing non-dysplastic (Non-dys OL) and dysplastic OL (Dys OL). Methodology: This is a cross-sectional observational study. Paraffin-embedded tissue blocks of 28 specimens of Non-dys OL, 33 of Dys $\mathrm{OL}, 9$ of normal oral mucosa (NOM), 17 of inflammatory hyperplasia (IH), and 19 of oral squamous cell carcinomas (OSCC) were stained for Ki-67 and BMI-1 using immunohistochemistry. Results: A gradual increase in BMI-1 and $\mathrm{K}$-i67 expression was found in oral carcinogenesis. The immunolabeling for those markers was higher in OSCC when compared with the other groups (Kruskal-Wallis, $\mathrm{p}<0.05)$. Ki-67 expression percentage was higher in $\mathrm{OL}$ and in IH when compared with NOM (Kruskal-Wallis/Dunn, p<0.05). Increased expression of BMI-1 was also observed in OL when compared with NOM (Kruskal-Wallis/Dunn, $\mathrm{p}<0.05$ ). No differences were observed in expression of both markers when non-dysplastic and dysplastic leukoplakias were compared. A significant positive correlation between Ki-67 and BMI-1 was found (Spearman correlation coefficient, $R=0.26, p=0.01$ ). High-grade epithelial dysplasia was associated with malignant transformation (Chisquared, $p=0.03$ ). Conclusions: These findings indicate that BMI-1 expression increases in early oral carcinogenesis and is possibly associated with the occurrence of dysplastic changes. Furthermore, our findings indicate that both $\mathrm{Ki}-67$ and BMI-1 are directly correlated and play a role in initiation and progression of OSCC.

Keywords: Leukoplakia, oral. Clinical evolution. Carcinoma, squamous cell.

${ }^{1}$ Universidade Federal do Rio Grande do Sul, Faculdade de Odontologia, Departamento de Odontologia Conservadora, Porto Alegre, Rio Grande do Sul, Brasil.

${ }^{2}$ Universidade Federal do Rio Grande do Sul, Faculdade de Medicina, Departamento de Patologia, Porto Alegre, Rio Grande do Sul, Brasil.

${ }^{3}$ University of Michigan, Department of Periodontics and Oral Medicine, Laboratory of Epithelial Biology, Ann Arbor, Michigan, United States of America. 


\section{Introduction}

Oral leukoplakia $(\mathrm{OL})$ is a lesion with a risk of malignant transformation ranging from $0.13 \%$ to $17.5 \% .{ }^{1}$ Histopathologically, OL is characterized by a variety of epithelial changes, including dysplasia. The presence of epithelial dysplasia is considered the most important predictive factor for OL prognosis. ${ }^{1-3}$

Although many biological markers have been explored, no reliable ones have yet been established for predicting malignant transformation of $\mathrm{OL}$, thus necessitating additional studies to increase our knowledge of the biological processes underlying OL and oral carcinogenesis. ${ }^{4} \mathrm{Ki}-67$ is a nuclear protein expressed in the $\mathrm{G} 1, \mathrm{~S}, \mathrm{G} 2$, and $M$ phases of the cell cycle, and its expression reflects the total growth fraction in tissues. ${ }^{5} \mathrm{Ki}-67$ expression correlates with the severity of epithelial dysplasia and histological grading of oral squamous cell carcinoma (OSCC). ${ }^{6,7}$ Another protein named BMI-1, which mediates gene silencing by regulating chromatin structure, ${ }^{8,9}$ plays a central role in cell cycle regulation and cell immortalization, as well as cell senescence and epithelial-mesenchymal transition (EMT). ${ }^{10,11}$ BMI-1 is associated with the initiation and progression of various tumors, including oropharyngeal, ${ }^{10}$ nasopharyngeal, ${ }^{11}$ and prostate ${ }^{12}$ cancers. Furthermore, increased BMI-1 expression was found in bronchial premalignant lesions as well as squamous cell carcinoma (SCC), indicating that its expression in neoplastic cells may be an early event in lung carcinogenesis. ${ }^{13}$ BMI-1 is also overexpressed in OSCC cells when compared with normal oral mucosa cells and has been presumed to influence proliferation and immortalization of epithelial cells in oral carcinogenesis. ${ }^{14}$

This study aimed to evaluate cell proliferation and immortalization in OL by studying $\mathrm{Ki}-67$ and BMI-1 expression in non-dysplastic (Non-dysOL) and dysplastic (DysOL) cases.

\section{Methodology}

\section{Patients and tissue specimens}

Ninety-eight cases of OL reported between 2000 and 2014 were selected for this study. Tissue samples were obtained from the archives of the Laboratories of Pathology of the Hospital de Clínicas de Porto Alegre and the School of Dentistry of the Federal
University of Rio Grande do Sul considering the clinical impression of leukoplakia. The study protocol was approved by Human Research Ethics Committee (CAAE 26759114900005327).

Information on demographics, risk factors, clinical presentation, treatment, and prognosis are shown in Table 1. Moreover, histological slides were revised to exclude cases incompatible with $\mathrm{OL}$ and cases with incomplete information in medical records or insufficient material for sampling. Descriptive histopathological diagnosis such as atrophy, acanthosis, epithelial hyperplasia, hyperkeratosis, and epithelial dysplasia were considered microscopic features of a clinical diagnosis of leukoplakia. After selection, the medical records were evaluated to confirm the clinical hypothesis and the final diagnosis of leukoplakia after clinical and microscopic correlation. Cases of in situ carcinoma were excluded. After that, 61 cases of OL were included for analysis (Figure 1). Nine cases of normal oral mucosa (NOM) obtained during surgical removal of unerupted third molars and, 17 cases of inflammatory hyperplasia (IH), and 19 cases of OSCC were used as comparison groups. IH cases were included as a reference for benign lesions that show an increased cell proliferation without the potential for malignant transformation.

\section{Clinical and follow up data}

Clinical data regarding lesion location, clinical presentation and lesion size were obtained from the clinical forms of patients seen in the School of Dentistry. Patients who did not present new lesions and maintained the clinical characteristics and/or OSCC development during the follow-up period were considered as having good prognosis. Patient who presented new lesions, increased lesion size, changes in surface and/or color, as well as those who developed OSCC were considered as having poor prognosis.

\section{Histopathological analysis}

All selected samples were fixed in $10 \%$ neutral formalin and embedded in paraffin. Five-micrometer H\&E (hematoxylin and eosin) stained sections were blindly reviewed by two pathologists (V.C.C. and I.P.K.). The epithelial dysplasia in OL samples was graded according to the criteria and definition proposed by Reibel, et al. ${ }^{15}$ (2017) and Kujan, et al. ${ }^{16}$ (2006). A consensus was reached in cases that were graded differently by the two pathologists. 


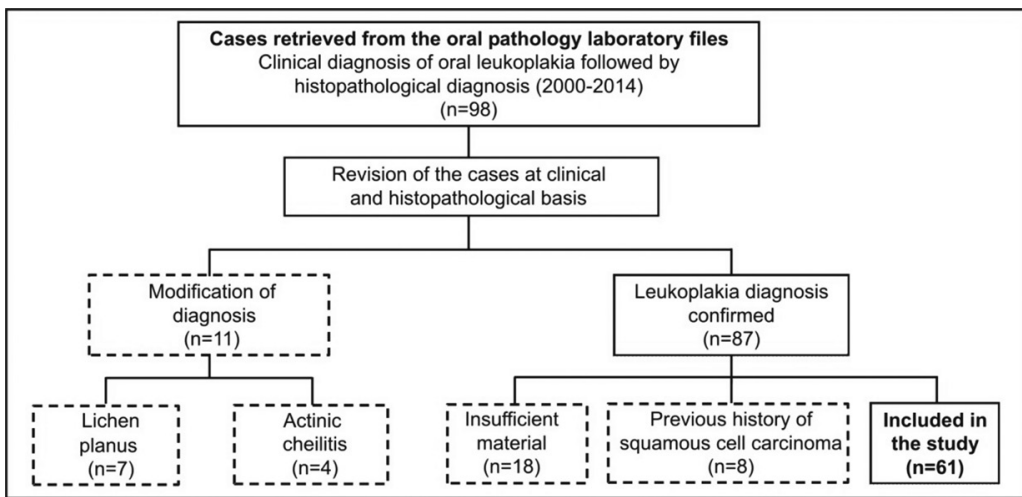

Figure 1- Flowchart of sampling strategy, depicting the criteria to select the study sample. After revision, the cases in which oral leukoplakia was confirmed were subjected to a strict evaluation to define if the amount of tissue was enough to prepare the required number of histological sections. Cases with previous history of squamous cell carcinoma were discarded

\section{Immunohistochemistry}

Tissue sections were subjected to immunohistochemical staining for BMI-1 and $\mathrm{Ki}-67$ antigens. Shortly after, blocks were sectioned (3 $\mu \mathrm{m})$ and placed on silanized slides. The slides were subsequently deparaffinized in xylene and hydrated in descending grades of ethanol. Antigen retrieval for $\mathrm{Ki}-67$ was performed for $18 \mathrm{~h}$ in low $\mathrm{pH}$ solution in a $90^{\circ} \mathrm{C}$ water bath, and for BMI-1, Tris-HCl buffer $(\mathrm{pH} 8.5)$ for $20 \mathrm{~min}$ at $98^{\circ} \mathrm{C}$ was used for the water bath. The slides were then incubated with the primary antibodies: Ki-67 (MIB-1, DAKO, 1:50, $1 \mathrm{~h}$ ) and BMI-1 (ab14389, Abcam, 1:100, 1 h). The EnVision (DakoCytomation, Carpinteria, CA, USA) was used as the detection system. The sections were then incubated with diaminobenzidine tetrahydrochloride (DAB, Novocastra, Newcastle, UK) and counterstained with Mayer's hematoxylin. The primary antibody was omitted for the negative control. The human appendix and reactive lymph node tissue were used as positive controls for BMI-1 and Ki-67, respectively. Only nuclear brown staining was considered as positive marking, regardless of the color intensity. ${ }^{17,18}$

\section{Immunostaining evaluation}

Images of the selected fields were captured using a conventional light microscope (CX41RF model, Olympus Latin America, Inc., Miami, Florida, USA) coupled to a camera (QColor 5, Coolet, RTV, Olympus Latin America, Inc., Miami, Florida, USA) and connected to a computer (Dimension 5150, Dell, Porto Alegre, RS, Brazil). Images were analyzed using the QCapture software program (Quantitative Imaging Corporation, Inc., Surrey, DC, Canada, version 2.81). Immunohistochemical evaluation was performed under high-power magnification $(\times 400)$. Nuclear staining was considered for positivity, regardless of staining intensity. Ki-67 were counted and classified based on Gonzalez-Moles, et al. ${ }^{5}$ (2000). The quantitative analysis involved the analysis of images of the slides using the same aforementioned imaging system. The labeling index (LI) was determined by the percentage of labeled nuclei per 1000 cells of all specimens of each group. ${ }^{5}$ BMI-1 was analyzed semi-quantitatively using scores based on the percentage of positive cells. To each case was assigned a score as follows: 1 (up to $50 \%$ positive cells - low), 2 (50 - 80\% - moderate), and 3 (over $80 \%$ - high). ${ }^{19}$

\section{Statistical analysis}

The Kruskal-Wallis test, followed by Dunn's test, was used for multiple comparisons and the Chisquare test was used for comparisons of scores distribution among the groups. Student $t$ /ANOVA and Mann-Whitney/Kruskal Wallis tests were used to assess the influence of $\mathrm{OL}$ characteristics on $\mathrm{Ki}$ 67 and BMI-1 expression, respectively. Spearman's correlation analysis was conducted to determine the relationship between BMI-1 and $\mathrm{Ki}-67$ expression. The SPSS Statistics software, 18.0 Version, was used for statistical analysis, and $\mathrm{p}$ value threshold used was $5 \%$.

\section{Results}

\section{Demographic and clinical characteristics}

Table 1 shows the demographic and clinical characteristics of the OL and OSCC patients. The cases were divided into two groups, namely "tongue or floor of the mouth" and "other sites", according to the lesion site. ${ }^{20}$ The tongue or floor of the mouth 
Table 1- Demographic and clinical characteristics of the OL and OSCC patient

\begin{tabular}{|c|c|c|c|}
\hline & OL & oscc & $p$ \\
\hline \multicolumn{4}{|l|}{ CHARACTERISTIC } \\
\hline All patients, no.(\%) & $61(76.25)$ & $19(23.75)$ & \\
\hline \multicolumn{4}{|l|}{ Age, years } \\
\hline Mean & 58.0 & 59.4 & $0.65^{*}$ \\
\hline Standard deviation & 12.8 & 10.9 & \\
\hline Range (minimum-maximum) & $26-81$ & $39-82$ & \\
\hline \multicolumn{4}{|l|}{ Gender, no(\%) } \\
\hline Female & $26(42.6)$ & $6(31.6 \%)$ & $0.56^{* *}$ \\
\hline Male & $35(57.4)$ & $13(68.4 \%)$ & \\
\hline \multicolumn{4}{|l|}{ Tobacco habits, no(\%) } \\
\hline Never & $8(16.3)$ & $2(13.3 \%)$ & $0.71^{* *}$ \\
\hline Past and present & $41(83.7)$ & $13(86.7 \%)$ & \\
\hline Unknown & 12 & 4 & \\
\hline \multicolumn{4}{|l|}{ Alcohol consumption, no(\%) } \\
\hline Never & $8(17.4)$ & $3(25.0 \%)$ & $0.68^{* *}$ \\
\hline Past and present & $38(82.6)$ & $9(75.0 \%)$ & \\
\hline Unknown & 15 & 7 & \\
\hline \multicolumn{4}{|l|}{ Location, no(\%) } \\
\hline Tongue / floor of the mouth & $19(31.6)$ & $12(63.2 \%)$ & $0.02^{* *}$ \\
\hline Other locations & $41(68.4)$ & $7(36.8 \%)$ & \\
\hline Unknown & 1 & 0 & \\
\hline \multicolumn{4}{|l|}{ Clinical type, no(\%) } \\
\hline Homogeneous & $32(60.4)$ & _ & - \\
\hline Non homogeneous & $21(39.6)$ & - & \\
\hline Unknown & 8 & _ & \\
\hline \multicolumn{4}{|l|}{ Lesion size, no(\%) } \\
\hline$<2 \mathrm{~cm}$ & $30(60.0)$ & - & - \\
\hline$\geq 2 \mathrm{~cm}$ & $20(40.0)$ & - & \\
\hline Unknown & 11 & - & \\
\hline \multicolumn{4}{|l|}{ TNM, no(\%) } \\
\hline $\mid / I I$ & _ & $5(27.8 \%)$ & _ \\
\hline III/IV & - & $13(72.2 \%)$ & \\
\hline Unknown & _ & 1 & \\
\hline \multicolumn{4}{|c|}{ Presence of epithelial dysplasia, no(\%) } \\
\hline No & $28(45.9)$ & _- & - \\
\hline Yes & $33(54.1)$ & - & \\
\hline \multicolumn{4}{|c|}{ Grade of epithelial dysplasia, no (\%) } \\
\hline Absent & $28(45.9)$ & - & - \\
\hline Low grade & $22(36.1)$ & - & \\
\hline High grade & $11(18.0)$ & _ & \\
\hline
\end{tabular}

*Student's t test; ${ }^{* *}$ Chi-square test

group had a significantly higher percentage of OSCC cases (Student's t test, $\mathrm{p}=0.02$ ) when compared with OL cases. Regarding prognosis, twenty-two (55.0\%) patients had good prognosis and $18(45.0 \%)$, poor prognosis.

Table 2 shows the characteristics of OL without and with OSCC development during the follow-up period ranging from 12 to 156 months (56.9 \pm 33.0$)$. Followup information was not available in 21 cases $(34.4 \%)$, whereas it was available for 40 OL patients $(65.5 \%)$. Four of the $40 \mathrm{OL}$ patients $(10.0 \%)$ developed OSCC, resulting in a $2.1 \%$ annual malignant transformation 
Table 2- Demographic and clinical characteristics of the OL with and without OSCC development

\begin{tabular}{|c|c|c|c|}
\hline & $\begin{array}{c}\text { OL patients without OSCC } \\
\text { development }\end{array}$ & $\begin{array}{c}\text { OL patients with OSCC } \\
\text { development }\end{array}$ & p \\
\hline \multicolumn{4}{|l|}{ Age } \\
\hline Mean (SD) & $56.3(13.0)$ & $52.7(15.9)$ & $0.61^{*}$ \\
\hline Min-Max & $26-79$ & $31-68$ & \\
\hline \multicolumn{4}{|l|}{ Gender } \\
\hline Male & $23(63.9)$ & $2(50.0)$ & $0.62^{* \star}$ \\
\hline Female & $13(36.1)$ & $2(50.0)$ & \\
\hline \multicolumn{4}{|l|}{ Location } \\
\hline Tongue/floor of the mouth & $11(30.6)$ & $3(75.0)$ & $0.11^{*}$ \\
\hline Others & $25(69.4)$ & $1(25.0)$ & \\
\hline \multicolumn{4}{|l|}{ Clinical type } \\
\hline Homogeneous & $20(64.5)$ & $1(33.3)$ & $0.54^{\star *}$ \\
\hline Non-homogeneous & $11(35.5)$ & $2(66.7)$ & \\
\hline Unknown & 5 & 1 & \\
\hline \multicolumn{4}{|l|}{ Lesion size } \\
\hline$<2 \mathrm{~cm}$ & $17(54.8)$ & $1(50.0)$ & $1.00^{\star *}$ \\
\hline$\geq 2 \mathrm{~cm}$ & $14(45.2)$ & $1(50.0)$ & \\
\hline Unknown & 5 & 2 & \\
\hline \multicolumn{4}{|c|}{ Presence of epithelial dysplasia } \\
\hline No & $17(47.2)$ & $1(25.0)$ & $0.01^{* *}$ \\
\hline Yes & $19(52.8)$ & $3(75.0)$ & \\
\hline \multicolumn{4}{|l|}{ Epithelial dysplasia grade } \\
\hline Absent & $18(50.0)$ & $1(25.0)$ & $0.03^{\star *}$ \\
\hline Low risk & $12(33.3)$ & $0(0.0)$ & \\
\hline High risk & $6(16.7)$ & $3(75.0)$ & \\
\hline
\end{tabular}

*Student's t test; ${ }^{* *}$ Chi-square test

rate. Of these 4 patients, $3(75.0 \%)$ patients underwent malignant transformation in the tongue or floor of the mouth and exhibited a high grade dysplasia (Chi-square test, $\mathrm{p}<0.01$ ).

\section{Immunohistochemical analysis}

$\mathrm{Ki}-67$ expression increases in $\mathrm{IH}, \mathrm{OL}$ and $\mathrm{OSCC}$ (Table 3).

Ki-67 immunolabeling data is shown in Figure 2. There was a gradual increase in Ki-67 expression (ANOVA/Tukey, p<0.01) through NOM (10.2\%), IH (29.4\%), Non-dysOL (33.1\%), DysOL (36.3\%) and OSCC (62.8\%). Moreover, cell proliferation was higher (ANOVA/Tukey, $\mathrm{p}<0.01$ ) through NOM to OSCC. Comparisons among different grades of epithelial dysplasia showed no statistically significant differences (Kruskal Wallis, $\mathrm{p}>0.05$ ). Representative images of Ki-67 immunolabeling are shown in Figure 2.

BMI-1 expression increases in $\mathrm{IH}, \mathrm{OL}$ and OSCC (Table 3).

Increasing positivity was observed for BMI-1 through NOM (1.7\%), IH (2.1\%), Non-dysOL (2.4\%), DysOL (2.5\%) and OSCC (2.8\%), agreeing with the Ki67 expression pattern. Non-dysOL cases showed lower BMI-1 immunolabeling when compared with the DysOL cases, although this difference was not statistically significant. However, the means were statistically higher (Kruskal Wallis, $\mathrm{p}<0.01$ ) in OL when compared with that in NOM, and in OSCC, when compared with that in NOM, IH and OL. Representative images of BMI-1 immunolabeling are shown in Figure 2.

\section{Correlation between BMI-1 and Ki-67 expression}

Spearman's correlation coefficients were estimated to determine if BMI-1 expression could be associated with changes in cell proliferation. BMI-1 expression directly correlated with Ki-67 expression (Spearman's correlation, $\mathrm{R}=0.26, \mathrm{p}=0.01)$. 
Association of Ki-67 and BMI-1 immunolabeling with OL clinical characteristics and histopathological changes (Table 4)

Higher Ki-67 and BMI-1 expression was observed in lesions in the tongue and floor of the mouth, epithelial dysplasia, OSCC development and poor clinical evolution; however, the associations were not statistically significant.
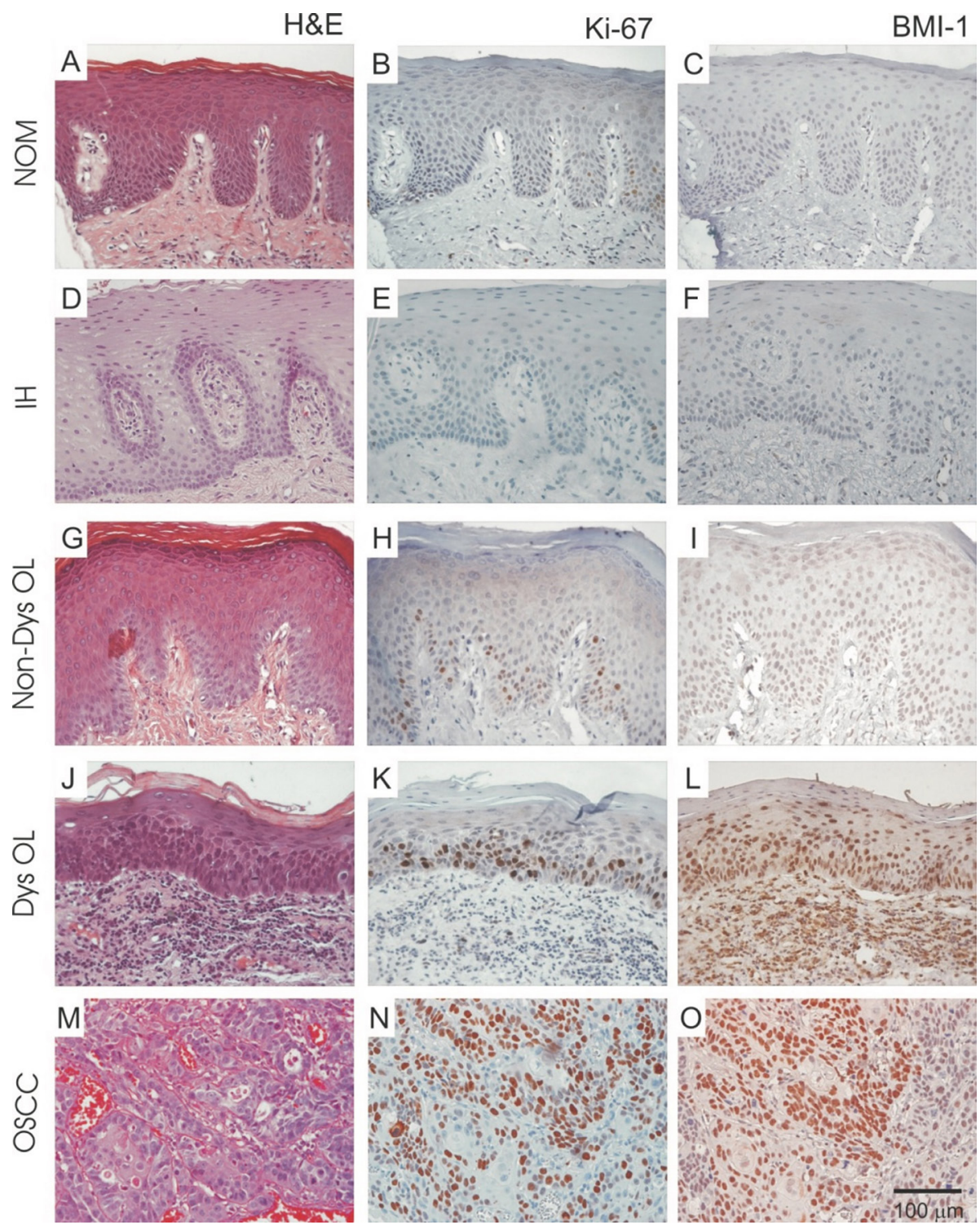

Figure 2- Gradual increase of Ki-67 and BMI-1 expression is observed from to normal oral mucosa (NOM) to oral squamous cell carcinoma (OSCC). Representative photomicrographs of NOM, inflammatory hyperplasia (IH), non-dysplastic oral leukoplakia (Non-dys $\mathrm{OL}$ ), dysplastic oral leukoplakia (Dys OL) and OSCC. Original magnification $\times 400$

Table 3- Percentage of immunopositive cells for Ki-67 and BMI-1 in normal oral mucosa (NOM), inflammatory hyperplasia (IH), and oral leukoplakia (OL)

\begin{tabular}{lcccccc}
\hline & NOM & IH & Non-dys OL & Dys OL & SCC & p \\
\hline Ki-67 immunolabeling & & & & & & \\
Mean & $10.2^{\mathrm{A}}$ & $29.4^{\mathrm{B}}$ & $33.1^{\mathrm{B}}$ & $36.3^{\mathrm{B}}$ & $62.8^{\mathrm{C}}$ & $<0.01^{*}$ \\
\hline SD & 3.0 & 8.9 & 11.1 & 15.2 & 16.6 & \\
BMI-1 immunolabeling & & & & & & \\
Mean & $1.7^{\mathrm{A}}$ & $2.1^{\mathrm{B}}$ & $2.4^{\mathrm{B}}$ & $2.5^{\mathrm{B}}$ & $2.8^{\mathrm{C}}$ & $<0.01^{\text {**}}$ \\
\hline SD & 0.5 & 0.9 & 0.7 & 0.7 & 0.4 & \\
\hline
\end{tabular}

${ }^{*}$ ANOVA/Tukey, ${ }^{* *}$ Kruskal-Wallis test/Dunn. Means followed by different uppercase letters are different from each other 
Table 4- Clinical and histopathological characteristics in $\mathrm{OL}$ cases and the association with the expression of Ki-67 and BMI-1

\begin{tabular}{|c|c|c|c|c|}
\hline & \multicolumn{2}{|c|}{ Ki-67(\%) } & \multicolumn{2}{|c|}{ BMI-1 (score) } \\
\hline & Mean(SD) & $\mathbf{p}$ & Mean(SD) & $\mathbf{p}$ \\
\hline \multicolumn{5}{|l|}{ Location } \\
\hline Tongue / floor of the mouth & $23.1(12.4)$ & $0.69^{a}$ & $2.6(0.6)$ & $0.42^{\mathrm{b}}$ \\
\hline Other locations & $38.3(11.5)$ & & $2.4(0.7)$ & \\
\hline \multicolumn{5}{|l|}{ Clinical type } \\
\hline Homogeneous & $32.3(14.5)$ & $0.24^{\mathrm{a}}$ & $2.5(0.7)$ & $0.84^{b}$ \\
\hline Non-homogeneous & $27.7(12.8)$ & & $2.5(0.6)$ & \\
\hline \multicolumn{5}{|l|}{ Lesion size } \\
\hline$<2 \mathrm{~cm}$ & $24.7(12.9)$ & $0.39^{a}$ & $2.4(0.7)$ & $0.52^{b}$ \\
\hline$\geq 2 \mathrm{~cm}$ & $28.4(13.3)$ & & $2.6(0.6)$ & \\
\hline \multicolumn{5}{|c|}{ Presence of epithelial dysplasia } \\
\hline No & $33.1(11.1)$ & $0,58^{\mathrm{a}}$ & $2.4(0.7)$ & $0.44^{b}$ \\
\hline Yes & $36.3(15.2)$ & & $2.5(0.7)$ & \\
\hline \multicolumn{5}{|c|}{ Grade of epithelial dysplasia } \\
\hline Absent & $33.1(11.1)$ & $0.08^{c}$ & $2.4(0.1)$ & $0.37^{\mathrm{d}}$ \\
\hline Low grade & $33.0(15.7)$ & & $2.4(0.2)$ & \\
\hline High grade & $43.0(12.4)$ & & $2.7(0.1)$ & \\
\hline \multicolumn{5}{|l|}{ OSCC development } \\
\hline No & $25.4(12.6)$ & $0.24^{\mathrm{a}}$ & $2.3(0.7)$ & $0.26^{b}$ \\
\hline Yes & $33.5(14.9)$ & & $2.6(1.0)$ & \\
\hline \multicolumn{5}{|l|}{ Clinical evolution } \\
\hline Good & $24.7(12.9)$ & $0.39^{a}$ & $2.3(0.6)$ & $0.23^{b}$ \\
\hline Poor & $24.8(13.3)$ & & $2.5(0.8)$ & \\
\hline
\end{tabular}

aStudent's t test; 'Mann Whitney's test; 'ANOVA; ' ${ }^{\mathrm{d}}$ Kruskal-Wallis

\section{Discussion}

Oral carcinogenesis is a complex process resulting from various genetic and epigenetic changes. BMI-1 overexpression in OSCC cells has been suggested to be associated with an increased cell proliferation ${ }^{14}$ and to be a predictive of tumorigenesis. ${ }^{21,22}$ Interestingly, statistically significant changes were observed in early stages of carcinogenesis. ${ }^{21,22}$ Moreover, BMI-1 immunolabeling levels were directly associated with cell proliferation in epithelium during carcinogenesis. ${ }^{23}$ To the best of our knowledge, this study is the first to assess $\mathrm{Ki}-67$ and BMI-1 expression in OL. ${ }^{19}$ As expected, the expression of these markers was increased in OL when compared with NOM.

BMI-1 is involved in the transcriptional repression of Hox genes, thus affecting stem cell self-renewal, embryonic development, and proliferation. ${ }^{24,25}$ Our results show that BMI-1 expression increases during carcinogenesis. However, BMI-1 immunolabeling analysis showed no differences between $\mathrm{OL}$ and $\mathrm{IH}$. OL presented a higher and statistical positivity of
BMI-1 when compared with NOM. Our results agrees with those of Kang, et al. ${ }^{14}$ (2007), who reported that increased BMI-1 expression was associated with dysplastic changes during oral carcinogenesis. The role of BMI-1 in EMT demonstrated in previous studies with breast cancer cells further support our findings. Moreover, BMI-1 overexpression in cancer cells has been reported to activate PI3K/AKT signaling pathway, and induce cell migration and metastasis. ${ }^{26,27}$

Liu, et al. ${ }^{28}$ (2012) found that BMI-1 expression was associated with the development of oral cancer in patients with $\mathrm{OL}$, suggesting that immunohistochemical marker could be used as a predictor of OL transformation. In that study, approximately $13 \%$ of 135 OL patients demonstrating BMI-1 positivity developed OSCC when compared with $10.3 \%$ patients negative for BMI-1. In our study, $10.0 \%$ of OL patients who were followed-up developed OSCC. In these patients, the presence of high grade dysplasia was found to be a predictor for OSCC development. The same group of patients displayed an increased Ki-67 and BMI1 expression; however, this was not statistically significant. Regarding the lesion site, three of the 
four lesions were located in the tongue/floor of the mouth, reinforcing that lesions at these sites present a more aggressive behavior. ${ }^{20}$ The annual malignant transformation rate observed in our study agrees with that reported by other recent studies. ${ }^{20} \mathrm{An}$ increased cell proliferation is well known to be one of the main events of carcinogenesis. ${ }^{29,30}$ Our findings showed an increased percentage of $\mathrm{Ki}-67$ positive cells in NondysOL and DysOL. Moreover, cell proliferation was higher in OSCC when compared with NOM.

Although the immunoexpression of $\mathrm{Ki}-67$ was slightly higher in DysOL than in Non-dysOL, the difference was not statistically significant, as found in previous studies. ${ }^{30,31}$ Furthermore, the same study showed that Ki-67 expression was progressively higher depending on the degree of epithelial dysplasia. ${ }^{32}$ Therefore, our findings reinforce that $\mathrm{Ki}-67$ expression is a valuable predictive marker for oral leukoplakia progression, reinforcing the presence of mitosis in the upper half of the epithelium as an important criterion in the morphological analysis, as recommended by previous studies. ${ }^{6,33}$

The other important result was the significant correlation found between Ki-67 and BMI-1 immunolabeling. This may be attributed to the role of BMI-1 in the regulation of cell proliferation by suppressing INK4a expression, a locus that triggers senescence in human somatic cells. ${ }^{34}$ Therefore, the switch between differentiation and epithelialmesenchymal transition, which depends on genetic and epigenetic events, is modulated by the control of cell growth, survival, angiogenesis, and motility. The balance of cross-talk between these signaling pathways is the basis for acquiring a malignant phenotype and progression to OSCC. Despite the large number of studies on this subject, the knowledge about individual factors must be improved to develop strategies for cancer prevention. ${ }^{35}$

To the best of our knowledge, this study is the first to report the correlation between $\mathrm{Ki}-67$ and BMI-1 expression in OL. Based on the results, cell proliferation and changes towards epithelial-tomesenchymal transition are likely related events during carcinogenesis. The increased expression of BMI-1 in the early stages of development of oral carcinogenesis indicates its potential use as a marker of preneoplastic oral lesions.

\section{Conclusion}

The findings of this study indicate that BMI-1 expression increases in early oral carcinogenesis and that it may be associated with the occurrence of dysplastic changes. Furthermore, our findings indicate that both Ki-67 and BMI-1 are directly correlated and possibly play a role in initiation and progression of oscC.

\section{Acknowledgements}

The authors would like to thank to Flávia Rejane Giusti for excellent technical support and to the National Council for Scientific and Technological Development (CNPq) the personal research grant to the first author (IPK). Manoela Domingues Martins is a research fellow funded by the Brazilian National Council for Scientific and Technological Development (CNPq). This study was funded by the Post-Graduate Research Group of the Hospital de Clínicas de Porto Alegre (GPPG/FIPE 14-0050).

\section{Authors' Contributions}

Klein, Isadora Peres: Conceptualization (Lead); Data curation (Lead); Formal analysis (Lead); Funding acquisition (Supporting); Investigation (Lead); Methodology (Lead); Project administration (Lead); Software (Supporting); Validation (Equal); Visualization (Equal); Writing-original draft (Lead); Writing-review \& editing (Equal); Meurer, Luise: Project administration (Supporting); Visualization (Supporting); Danilevicz, Chris Krebs: Methodology (Supporting); Project administration (Supporting); Visualization (Supporting); Squarize, Cristiane Helena: Writing-original draft (Supporting); Writingreview \& editing (Supporting); Martins, Manoela Domingues: Investigation (Supporting); Methodology (Supporting); Project administration (Supporting); Visualization (Supporting); Writing-original draft (Supporting); Writing-review \& editing (Supporting). Carrard, Vinicius Coelho: Conceptualization (Lead); Data curation (Supporting); Formal analysis (Supporting); Funding acquisition (Lead); Investigation (Supporting); Methodology (Supporting); Project administration (Supporting); Resources (Lead); Software (Supporting); Supervision (Lead); Validation (Equal); Visualization (Equal); Writing-original draft (Supporting); Writing-review \& editing (Lead). 


\section{References}

1- Reibel J. Prognosis of oral pre-malignant lesions: significance of clinical, histopathological, and molecular biological characteristics. Crit Rev Oral Biol Med. 2003;14(1):47-62. doi: 10.1177/154411130301400105 2- Nasser W, Flechtenmacher Chr, Holzinger D, Hofele Chr, Bosch FX. Aberrant expression of p53, p16INK4a and Ki-67 as basic bio- marker for malignant progression of oral leukoplakias. J Oral Pathol Med. 2011;40(8):629-35. doi: 10.1111/j.1600-0714.2011.01026.x

3- Holmstrup $P$, Vedtofte $P$, Reibel J, Stoltze K. Long-term treatment outcome of oral premalignant lesions. Oral Oncol. 2006;42(5):461-74. doi: 10.1016/j.oraloncology.2005.08.011

4- Monteiro de Oliveira Novaes JA, William WN Jr. Prognostic factors, predictive markers and cancer biology: the triad for successful oral cancer chemoprevention. Future Oncol. 2016;12(20):2379-86. doi: 10.2217/fon-2016-0168

5- Gonzalez-Moles MA, Ruiz-Avila I, Rodriguez-Archilla A, Martinez-Lara I. Suprabasal expression of $\mathrm{Ki}-67$ antigen as a marker for the presence and severity of oral epithelial dysplasia. Head Neck. 2000;22(7):65861. doi: 10.1002/1097-0347(200010)22:7<658: :aid-hed3>3.0.co;2-a 6- Dwivedi N, Chandra S, Kashyap B, Agarwal A. Suprabasal expression of $\mathrm{Ki}-67$ as a marker for the severity of oral epithelial dysplasia and oral squamous cell carcinoma. Contemp Clin Dent. 2013;4(1):7-12. doi: 10.4103/0976-237X.111586

7- Piattelli A, Rubini C, Fioroni M, Iezzi G, Santinelli A. Prevalence of p53, bcl-2, and Ki-67 immunoreactivity and of apoptosis in normal oral epithelium and in premalignant and malignant lesions of the oral cavity. J Oral Maxillofac Surg. 2002;60(5):532-40. doi: 10.1053/ joms.2002.31851

8- Giudice FS, Pinto DS Jr, Nör JE, Squarize CH, Castilho RM. Inhibition of histone deacetylase impacts cancer stem cells and induces epithelial-mesenchyme transition of head and neck cancer. PloS One. 2013;8(3):e58672. doi: 10.1371/journal.pone.0058672

9- Tie F, Furuyama T, Prasad-Sinha J, Jane E, Harte PJ. The Drosophila Polycomb Group proteins ESC and $\mathrm{E}(\mathrm{Z})$ are present in a complex containing the histone-binding protein $\mathrm{p} 55$ and the histone deacetylase RPD3. Development. 2001;128(2):275-86.

10- Huber GF, Albinger-Hegyi A, Soltermann A, Roessle M, Graf N, Haerle $\mathrm{SK}$, et al. Expression patterns of Bmi-1 and p16 significantly correlate with overall, disease-specific, and recurrence-free survival in oropharyngeal squamous cell carcinoma. Cancer. $2011 ; 117(20)$ :465970. doi: $10.1002 /$ cncr.26100

11- Song LB, Li J, Liao WT, Feng Y, Yu CP, Hu LJ, et al. The polycomb group protein $\mathrm{Bmi}-1$ represses the tumor suppressor PTEN and induces epithelial-mesenchymal transition in human nasopharyngeal epithelial cells. J Clin Invest. 2009;119(12):3626-36. doi: 10.1172/JCI39374

12- Lukacs RU, Memarzadeh S, Wu H, Witte ON. BMI-1 is a crucial regulator of prostate stem cell self-renewal and malignant transformation. Cell Stem Cell. 2010;7(6):682-93. doi: 10.1016/j. stem.2010.11.013

13- Breuer RH, Snijders PJ, Smit EF, Sutedja TG, Sewalt RG, Otte AP, et al. Increased expression of the $\mathrm{EZH} 2$ polycomb group gene in $\mathrm{BMI}-$ 1-positive neoplastic cells during bronchial carcinogenesis. Neoplasia. 2004;6(6):736-43. doi: 10.1593/neo.04160

14- Kang MK, Kim RH, Kim SJ, Yip FK, Shin KH, Dimri GP, et al. Elevated $\mathrm{Bmi}-1$ expression is associated with dysplastic cell transformation during oral carcinogenesis and is required for cancer cell replication and survival. Br J Cancer. 2007;96(1):126-33. doi: 10.1038/sj.bjc.6603529 15- Reibel J, Gale N, Hille J, Hunt JL, Lingen M, Muller S, et al. Oral potentially malignant disorders and oral epithelial dysplasia. In: El-Nagar AK, Chan JK, Grandis JR, Takata T, Slootweg PJ. WHO classification of head and neck tumours. Lyon: IARC Press; 2017. p.112-3.
16- Kujan O, Oliver RJ, Khaltab A, Roberts SA, Thakker N, Sloan P. Evaluation of a new binary system of grading oral epithelial dysplasia for prediction of malignant transformation. Oral Oncol. 2006;42(10):98793. doi: 10.1016/j.oraloncology.2005.12.014

17- Raaphorst FM, van Kemenade FJ, Fieret E, Hamer KM, Satijn $\mathrm{DP}$, Otte AP, et al. Cutting edge: polycomb gene expression patterns reflect distinct $B$ cell differentiation stages in human germinal centers. J Immunol. 2000;164(1):1-4. doi: 10.4049/jimmunol.164.1.1

18- Dutton A, Woodman CB, Chukwuma MB, Last JI, Wei W, Vockerodt $M$, et al. BMI-1 is induced by the Epstein-Barr virus oncogene LMP1 and regulates the expression of viral target genes in Hodgkin lymphoma cells. Blood. 2007;109(6):2597-603. doi: 10.1182/ blood-2006-05-020545

19- Hayry V, Mäkinen LK, Atula T, Sariola H, Mäkitie A, Leivo I, et al. BMI-1 expression predicts prognosis in squamous cell carcinoma of the tongue. $\mathrm{Br}$ J Cancer. 2010;102(5):892-7. doi: 10.1038/sj.bjc. 6605544 20- Van der Waal I. Potentially malignant disorders of the oral and oropharyngeal mucosa; terminology, classification and present concepts of management. Oral Oncol. 2009;45(4-5):317-23. doi: 10.1016/j.oraloncology.2008.05.016

21- Torres-Rendon A, Roy S, Craig GT, Speight PM. Expression of Mcm2, geminin and Ki67 in normal oral mucosa, oral epithelial dysplasias and their corresponding squamous-cell carcinomas. $\mathrm{Br} \mathrm{J}$ Cancer. 2009;100(7):1128-34. doi: 10.1038/sj.bjc.6604967

22- Gonzalez-Moles MA, Ruiz-Avila I, Gil-Montoya JA, Esteban F, Bravo $M$. Analysis of $\mathrm{Ki}-67$ expression in oral squamous cell carcinoma: why $\mathrm{Ki}-67$ is not a prognostic indicator. Oral Oncol. 2010;46(7):525-30. doi: 10.1016/j.oraloncology.2010.03.020

23- Ducrest AL, Szutorisz H, Lingner J, Nabholz M. Regulation of the human telomerase reverse transcriptase gene. Oncogene. 2002;21(4):541-52. doi: 10.1038/sj.onc. 1205081

24- Lessard J, Sauvageau G. BMI-1 determines the proliferative capacity of normal and leukaemic stem cells. Nature. 2003;423(6937):255-66. $10.1038 /$ nature 01572

25- Van der Lugt NM, Domen J, Linders K, van Roon M, RobanusMaandag $\mathrm{E}$, te Riele $\mathrm{H}$, et al. Posterior transformation, neurological abnormalities, and severe hematopoietic defects in mice with a targeted deletion of the bmi-1 proto-oncogene. Genes Dev. 1994;8(7):757-69. doi: $10.1101 /$ gad.8.7.757

26- Li H, Song F, Chen X, Li Y, Fan J, Wu X. BMI-1 regulates epithelialto-mesenchymal transition to promote migration and invasion of breast cancer cells. Int J Clin Exp Pathol. 2014;7(6):3057-64.

27- Yuan W, Yuan Y, Zhang T, Wu S. Role of BMI-1 in regulation of ionizing irradiation-induced epithelial-mesenchymal transition and migration of breast cancer cells. PloS One. 2015;10(3):e0118799. doi: $10.1371 /$ journal.pone.0118799

28- Liu W, Feng JQ, Shen XM, Wang HY, Liu Y, Zhou ZT. Two stem cell markers, ATP-binding cassette, G2 subfamily (ABCG2) and BMI-1, predict the transformation of oral leukoplakia to cancer: a long-term follow-up study. Cancer. 2012;118(6):1693-700. doi: 10.1002/ cncr. 26483

29- Gavish A, Krayzler E, Nagler R. Tumor growth and cell proliferation rate in human oral cancer. Arch Med Res. 2016;47(4):271-4. doi: 10.1016/j.arcmed.2016.07.007

30- Kannan S, Chandran GJ, Pillai KR, Mathew B, Sujathan K, Nalinakumary KR, et al. Expression of p53 in leukoplakia and squamous cell carcinoma of the oral mucosa: correlation with expression of Ki67. Clin Mol Pathol. 1996;49(3):M170-5. doi: 10.1136/mp.49.3.m170 31- Teresa DB, Neves KA, Neto CB, Fregonezi PA, Oliveira MR, Zuanon $\mathrm{JA}$, et al. Computer-assisted analysis of cell proliferation markers in oral lesions. Acta Histochem. 2007;109(5):377-87. doi: 10.1016/j. acthis.2007.03.007 
32- Takkem A, Barakat C, Zakaraia S, Zaid K, Najmeh J, Ayoub M, et al. $\mathrm{Ki}-67$ prognostic value in different histological grades of oral epithelial dysplasia and oral squamous cell carcinoma. Asian Pac J Cancer Prev. 2018;19(11):3279-86. doi: 10.31557/APJCP.2018.19.11.3279

33- Kumar KV, Chaithanya K, Punde P, Thorat A, Jangam AG, Deepth

$\mathrm{S}$. Comparative evaluation of imunohistochemical expression of $\mathrm{Ki}-67$ in oral lichen planus, oral leukoplakia and normal mucosa cases. J Int Oral Health. 2015;7(10):82-7.
34- Itahana K, Zou Y, Itahana Y, Martinez JL, Beausejour C, Jacobs JJ, et al. Control of the replicative life span of human fibroblasts by $p 16$ and the polycomb protein BMI-1. Mol Cell Biol. 2003;23(1):389- 401. doi: $10.1128 / \mathrm{mcb} \cdot 23.1 .389-401.2003$

35- Molinolo AA, Amornphimoltham P, Squarize $\mathrm{CH}$, Castilho RM, Pate $\mathrm{V}$, Gutkind JS. Dysregulated molecular networks in head and neck carcinogenesis. Oral Oncol. 2009;45(4-5):324-34. doi: 10.1016/j. oraloncology.2008.07.011 